\title{
Performance of a Two-Stage Membrane System for Bromelain Separation from Pineapple Waste Mixture as Impacted by Enzymatic Pretreatment and Diafiltration
}

\section{Mohd Zuhair Mohd Nor ${ }^{1,2 *}$, Lata Ramchandran', Mikel Duke $^{3}$ and Todor Vasiljevic ${ }^{1}$}

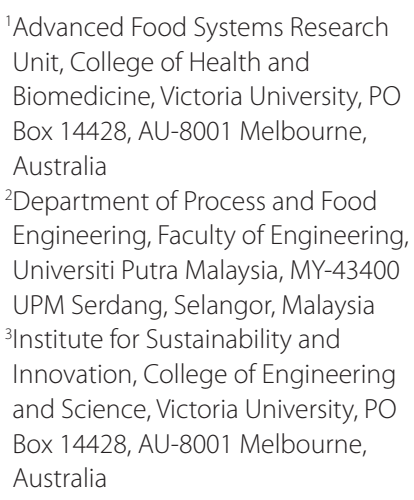

2Department of Process and Food Engineering, Faculty of Engineering, Universiti Putra Malaysia, MY-43400 UPM Serdang, Selangor, Malaysia ${ }^{3}$ Institute for Sustainability and Innovation, College of Engineering and Science, Victoria University, PO Box 14428, AU-8001 Melbourne, Australia

Received: 18 August 2017 Accepted: 20 December 2017
*Corresponding author:

Phone: +60389464303

Fax: +60389464440;

E-mail:zuhair@upm.edu.my

ORCID IDs: 0000-0001-5537-4251 (Nor), 0000-0001-7729-4949 (Ramchandran), 0000-0002-3383-0006 (Duke), 0000-0003-1395-7349 (Vasiljevic)

\begin{abstract}
SUMMARY
Membrane technology has been successfully applied for the purification of bromelain, a protease enzyme from pineapple. However, the current system operates less optimally in terms of flux and separation primarily due to properties of the feed, such as viscosity. Hence, in this study, enzymatic pretreatment and diafiltration operation were employed in a two-stage ultrafiltration (UF) system to enhance the performance of the purification and concentration process of bromelain enzyme from an extract of pineapple crude waste mixture (CWM). Pretreatment of the CWM extract using either pectinase or cellulase, or the combination of both, was applied and compared regarding the apparent viscosity reduction. Diafiltration step was introduced in UF stage 2 and observations on the flux performance, enzyme recovery and enzyme purity were made. A $12 \%$ apparent viscosity reduction was achieved when the CWM extract was pretreated with pectinase which led to 37-38\% improvement in the flux performance of both UF stages, as well as higher enzyme recovery in UF stage 1 . The introduction of diafiltration mode in UF stage 2 managed to sustain high flux values while yielding 4.4 -fold enzyme purity (higher than a 2.5 -fold purity achieved in our previous work); however, high diluent consumption was needed. The outcomes of this study showed that the flux performance and bromelain separation can be enhanced by reducing the viscosity with the employment of enzymatic pretreatment and diafiltration operation. Thus, both techniques can be potentially applied in a large-scale membrane-based process for bromelain production.
\end{abstract}

Key words: bromelain, pineapple waste, ultrafiltration, purification, enzymatic pretreatment, diafiltration

\section{INTRODUCTION}

Tailored separations using semipermeable membranes enable fractionation of compounds primarily according to their size and can be applied in different fields including food processing and biotechnology industry (1). Membrane fractionation has allowed enhancement and purification of various proteins such as proteases from yellowfin tuna spleen (2), ovalbumin from chicken egg white (3), phosvitin from egg yolk (4), recombinant plant-made proteins from corn extracts (5) and an antioxidant peptide derived from sandfish (6). One promising protein that may be separated and purified by membranes is bromelain from pineapple extract (7). Bromelain is a generic name given to proteolytic enzymes found in vegetable tissues of pineapple (Ananas comosus) and other plants from Bromeliaceae family (8). The enzyme is found in the stem (EC 3.4.22.32), fruit (EC 3.4.22.33) as well as in other parts of pineapple (9). Besides being extensively used in therapeutic applications, bromelain has also been applied in numerous industrial uses such as a meat tenderizer, fruit anti-browning agent, bread dough improver, beer clarifier, tooth whitening agent, animal feed and cosmetic substance (10).

The application of membrane-based processes for the separation and concentration of bromelain from extract of various pineapple parts involved a dual-stage microfiltration (MF) and ultrafiltration (UF) $(11,12)$, which can be integrated with ammonium sulfate 
extraction and reverse micellar system $(13,14)$. However, fine tuning the membrane separation to avoid the use of additional compounds like ammonium sulfate serves a green technology option offering great advantages for bromelain production. In our previous work, we showed that bromelain purity could be increased 2.5-fold using a two-stage UF process, which consisted of ceramic membranes with molecular mass cut-off (MMCO) of 75 and $10 \mathrm{kDa}$, respectively (15). Despite the promising progress, current systems operate less optimally in terms of flux, which means greater membrane area is needed to achieve the desired production rate, which in turn leads to higher production cost. Flux decline and formation of a fouling layer limit membrane performance, primarily due to the presence of macromolecules impacting bulk properties such as viscosity, which translates to higher pump energy and plant capital cost. The viscosity of the feed is important in affecting flow behavior in the system, and lower feed viscosity leads to a greater mass transfer process through the membrane (16). Hence, reduction of the feed viscosity is required to increase flux and bromelain separation, which would lower the cost for large-scale bromelain production. This can be accomplished by altering the composition of the raw extract and/or optimizing the operating conditions (7). For example, feed enzymatic pretreatment and employment of diafiltration are valid techniques to enhance flux performance to reduce bromelain production costs.

Pretreatment of the feed to reduce viscosity requires alteration of the component properties. Although the targeted enzyme can be separated from the other components based on size exclusion, polysaccharides (particularly pectin) are usually responsible for high viscosity and fouling build-up during membrane processing, which in turn hinders the membrane performance particularly for bromelain separation (9). Thus, enzymatic pretreatment of the feed to hydrolyze the polysaccharides, prior to the membrane process, would enhance process performance by hindering rise in viscosity and fouling during operation. Furthermore, another approach to reduce feed viscosity and increase membrane flux is by applying diafiltration operation. Diafiltration involves the addition of fresh diluent to the retentate, which leads to dilution of permeable solutes while the targeted enzyme is retained (16). A 10-fold rise in the purity of proteases from yellowfin tuna spleen was yielded by employing a continuous diafiltration mode during UF process (17).

Nevertheless, little work has been undertaken to translate these working concepts to bromelain separation and concentration by membranes. Hence, the work presented here would address this and explore the effects of enzymatic pretreatment and diafiltration on flux performance while attempting to maintain the enzyme purity. Thus, the aim of this study is to investigate the feasibility of employing enzymatic pretreatment and diafiltration operation for an improved bromelain purification and concentration via a two-stage UF process.

\section{MATERIALS AND METHODS}

\section{Preparation of pineapple crude waste mixture extracts}

The preparation of the pineapple crude waste mixture (CWM) extract from the commercial grade pineapples (Ananas comosus L.) of Smooth Cayenne cultivars has been described in details in our previous works $(9,15,18)$ to represent a real form of raw materials obtained in the pineapple industry. The CWM extract was produced from a specific mass ratio of $28 \%$ crown, $57 \%$ peel and $15 \%$ core, which were blended (8011ES; Waring, Torrington, CT, USA) with an equal mass of cold Milli-Q ${ }^{\oplus}$ water (Merck Millipore, Darmstadt, Germany) for 3 min prior to filtration with cheesecloth and centrifugation (Avanti J-26S XPI; Beckman Coulter, Pasadena, CA, USA) at $10000 \times g$ at $4{ }^{\circ} \mathrm{C}$ for $20 \mathrm{~min}$. The obtained supernatant, named CWM extract, was subjected to various enzymatic pretreatments and the extract $\mathrm{pH}$ was adjusted to $\mathrm{pH}=7.0$ with $1.0 \mathrm{M}$ $\mathrm{NaOH}$ before the experiment starts. The $\mathrm{pH}$ adjustment was required to obtain optimal performance of flux and enzyme activity (15).

\section{Enzymatic pretreatment of the CWM extract}

Enzymatic pretreatment was carried out on the CWM extract to reduce its viscosity and subsequently improve the filtration process. The pretreatment involved the application of either pectinase (EC 3.2.1.15) from Aspergillus aculeatus with activity of $3800 \mathrm{U} / \mathrm{mL}$ (Sigma-Aldrich, Merck, St. Louis, MO, USA), cellulase (EC 3.2.1.4) from Trichoderma reesei with activity of $700 \mathrm{U} / \mathrm{g}$ (Sigma-Aldrich) or the combination of both, following a method by Carvalho et al. (19) with minor modifications. Approximately $500 \mathrm{~mL}$ of CWM extract was mixed with (in \%, by volume) either pectinase 0.01 , cellulase 0.05 or pectinase $0.01+$ cellulase 0.05 under constant stirring by a magnetic stirrer at room temperature $\left((20 \pm 2){ }^{\circ} \mathrm{C}\right)$ for $30 \mathrm{~min}$. No inactivation of the pectinase/cellulase enzymes at a high temperature (blanching) was performed after the pretreatment to avoid denaturation of the bromelain enzyme in the extract. The pretreated CWM extract was immediately subjected to viscosity analysis or UF process.

\section{Measurement of apparent viscosity of the pretreated CWM extract}

The apparent viscosity of the pretreated CWM extract was measured using a controlled stress/controlled strain (CS/CR) rheometer (MCR 301; Anton Paar GmbH, Graz, Austria) with a double gap cylinder geometry (DG.26.7/Q1; Anton Paar $\mathrm{GmbH}$ ) and a temperature controller (Anton Paar $\mathrm{GmbH}$ ). The apparent viscosity of the pineapple extracts was determined with the increment of shear rate from 0 to $500 \mathrm{~s}^{-1}(20)$. All determinations were performed at $(20 \pm 0.1)^{\circ} \mathrm{C}$, and the data obtained were analysed with supporting Rheoplus rheometer software (21). 


\section{Set-up for two-stage ultrafiltration}

The UF set-up in this study consisted of a tubular zirconium oxide $\left(\mathrm{ZrO}_{2}\right)$ membrane with $0.0055 \mathrm{~m}^{2}$ surface area (Pall Corporation, Port Washington, NY, USA), which was fitted into the membrane module (Membralox T1-70; Pall Corporation). The set-up was pressurized by a peristaltic pump (Masterflex L/S; Cole-Parmer, Vernon Hills, IL, USA).

The application of the two-stage UF for bromelain separation in this study followed the similar set-up in our previous works $(15,18)$. It was a two-stage batch cross-flow UF process comprised of two membranes: the first of $75 \mathrm{kDa}$ pore size in the UF stage 1 and the second of $10 \mathrm{kDa}$ in UF stage 2 . In UF stage 1 (prefiltration stage), the bromelain was separated from high molecular mass compounds and recovered in the permeate. In UF stage 2 (purification stage), the permeate containing bromelain from UF stage 1 was separated from low molecular mass compounds such as amino acids and pigments and concentrated as the retentate. The permeate was collected in the permeate tank and removed from the system while the retentate was recycled back to the feed tank in all experiments. All UF runs in this study were performed at a transmembrane pressure of $0.2 \mathrm{MPa}$, cross-flow velocity of $0.24 \mathrm{~m} / \mathrm{s}$ and temperature of $20^{\circ} \mathrm{C}$.

In all experimental runs (except for the UF stage 2 combined modes), the UF processes were performed until a final percentage of permeate recovery (PR) of $80 \%$ for UF stage 1 and a final volume reduction factor (VRF) of 5 in UF stage 2, respectively, were reached (15). These parameters can be described further by the following equations:

$$
\begin{gathered}
\mathrm{PR}=\frac{V_{\mathrm{p}}}{V_{\mathrm{f}}} \cdot 100 \\
\mathrm{VRF}=\frac{V_{\mathrm{f}}}{V_{\mathrm{r}}}
\end{gathered}
$$

where $V_{f} V_{p}$ and $V_{r}$ represent the volume of the initial feed, final permeate, and final retentate, respectively. The PR is used to indicate the feed extract that has been filtered from UF stage 1 , while the VRF is the ratio between the initial feed volume and the volume of resulting final retentate in UF stage 2 . These conditions were selected based on the suitability of this study and may not accurately represent operation on a larger scale since several factors should be taken into consideration, including the membrane area, the volume of the feed, operational set-up, number of filtration stages, etc.

The permeate flux $(J)$ was monitored up to PR of $80 \%$ in UF stage 1 or VRF of 5 in UF stage 2 , since after this point the flux would attain a steady-state (15). Permeate flux, J, was determined by the following equation (4):

$$
J=\frac{1}{A_{\mathrm{m}}} \cdot \frac{\Delta m}{\Delta t}
$$

where $A_{m}$ is the effective membrane area $\left(\mathrm{m}^{2}\right)$ and $(\Delta \mathrm{m} / \Delta t)$ is the permeate mass $\Delta m$ collected over time $\Delta t(\mathrm{~kg} / \mathrm{h})$.

After each experimental run, the ceramic membranes (Membralox) were cleaned with deionized water, $2 \%$ (by mass) $\mathrm{NaOH}$ and $1 \%$ (by mass) $\mathrm{HNO}_{3}$ at $60^{\circ} \mathrm{C}$ by following the cleaning procedures by the membrane supplier (22). Clean water flux measurement was also performed after cleaning to confirm the efficiency of the cleaning process.

\section{Combination of diafiltration and concentration mode in UF stage 2}

A diafiltration operational mode was introduced in UF stage 2 prior to concentration process. The purpose is to first dilute the bromelain in a diluent followed by concentrating it. The set-up of this combined mode during UF process followed an arrangement by Li et al. (17). The diafiltration mode included the addition of Milli-Q ${ }^{\circledR}$ water as the diluent into the feed tank to replace the loss of volume by permeate-loss and maintain the constant feed volume in the tank. The diafiltration process was performed until diafiltration volume factor (DVF) of 3 was achieved, which is defined as follows:

$$
D V F=\frac{V_{d}}{V_{f}}
$$

where $V_{d}$ is the volume of newly added diluent and $V_{f}$ is the initial volume of the feed.

Once DVF of 3 was achieved, the process of UF stage 2 was changed to the concentration mode by reducing the feed volume through the removal of the permeate from the system without diluent addition. The process in UF stage 2 was stopped after $\mathrm{VRF}=5$ was attained. Both test modes (diafiltration and concentration) were performed at a transmembrane pressure of $0.2 \mathrm{MPa}$, cross-flow velocity of $0.24 \mathrm{~m} / \mathrm{s}$ and temperature of $20^{\circ} \mathrm{C}$.

\section{Protein and enzyme analysis}

The total organic carbon (TOC) analyzer with total nitrogen (TN) detector (TOC-V; Shimadzu, Kyoto, Japan) was employed for the protein determination (23). It involved the dilution of the sample below $50 \mathrm{mg} / \mathrm{L}$ of nitrogen while using $50 \mathrm{mg} / \mathrm{L}$ of potassium nitrate as a standard solution to confirm the original calibration. The result was displayed as total nitrogen, and a conversion factor of 6.25 was used to calculate the protein content (expressed in $\mathrm{mg} / \mathrm{mL}$ ) from the obtained value.

The enzyme activity of all samples was determined by the casein digestion unit (CDU), using casein and L-tyrosine as a substrate and a standard, respectively (24). The assays were based on the proteolytic hydrolysis of the casein substrate. The absorbance of the clear filtrate (solubilized casein) was measured at $275 \mathrm{~nm}$ using a spectrophotometer (Libra S12; Biocrom, Holliston, MA, USA). One unit of enzyme activity was defined as the amount of enzyme releasing a product equivalent to $1 \mathrm{~g}$ of tyrosine per min per $\mathrm{mL}$ under the standard assay conditions of $37^{\circ} \mathrm{C}$ and $\mathrm{pH}=7.0$ for $10 \mathrm{~min}$ and expressed as CDU/mL. The specific activity (SA) of the enzyme was estimated based on the following equation as CDU per mg of protein. 


$$
\mathrm{SA}=\frac{\mathrm{EA}}{\mathrm{PC}}
$$

where EA is the enzyme activity, and PC is the protein content.

\section{Enzyme purity and enzyme recovery}

The determination of enzyme purification fold (PF) and enzyme recovery (ER) of permeate in UF stage 1 (prefiltration stage) and retentate in UF stage 2 (purification stage) was performed to evaluate the process efficiency. The measurements of PF and ER were based on the following two equations (14):

$$
P F=\frac{S A_{r}}{S A_{f}}
$$

and

$$
E R=\frac{E A_{p} \cdot V_{p}}{E A_{f} \cdot V_{f}} \cdot 100
$$

where $\mathrm{SA}_{f}$ and $\mathrm{SA}_{r}$ are the specific activities of the enzyme in the feed and retentate, respectively; $\mathrm{EA}_{\mathrm{f}}$ and $\mathrm{EA}_{\mathrm{p}}$ represent the enzyme activity in the feed and permeate, respectively, while $V_{f}$ and $V_{p}$ are the volume of feed and permeate, respectively.

\section{Membrane selectivity}

The effectiveness of solute fractionation in UF stage 2 (purification stage) was expressed by the equations by van Reis and Saksena (25). It involves the determination of transmission of enzyme or protein which was represented by the ratio of either the enzyme activity $(\mathrm{CDU} / \mathrm{mL})$ or the protein content $(\mathrm{mg} / \mathrm{mL})$ in the permeate in relation to those in the feed; and was determined by the apparent sieving coefficient $\left(S_{a}\right)$ as follows:

$$
S_{a}=\frac{c_{p}}{C_{f}}
$$

where $c_{p}$ is the solute concentration in the permeate and $c_{f}$ is the solute concentration in the bulk feed. The rejection of solutes by the membrane was represented by the observed rejection $\left(R_{\text {obs }}\right)$ in the following equation:

$$
R_{\mathrm{obs}}=1-\frac{c_{\mathrm{p}}}{C_{\mathrm{f}}}=1-S_{\mathrm{a}}
$$

The enzyme activity and protein content of the feed during the diafiltration and concentration mode in UF stage 2 in this study were modeled according to the following equations $(17,26)$ :

For diafiltration process:

$$
\frac{c_{f, i}}{c_{f, i 0}}=\exp \left[-\frac{V_{d}}{V_{f}} \cdot\left(1-R_{o b s, i}\right)\right]=\exp \left(-\frac{V_{d}}{V_{f}} \cdot S_{a, i}\right)
$$

For concentration process:

$$
\frac{c_{f, i}}{c_{f, i 0}}=\left(\frac{V_{f}}{V_{r}}\right)^{R_{o b s, i}}
$$

where $c_{f, i}$ is the concentration of solute in the feed during the process, and $c_{f, i}$ is the initial concentration of solute $i$ in the feed before the process.

The effectiveness of solute fractionation was expressed by selectivity $(\psi)$ which was calculated as follows:

$$
\psi=\frac{S_{\mathrm{a} 1}}{S_{\mathrm{a} 2}}
$$

where 1 stands for the preferentially transmitted solute (protein) and 2 stands for the preferentially retained solute (enzyme).

\section{Sodium dodecyl sulfate-polyacrylamide gel electrophoresis}

SDS polyacrylamide gel electrophoresis (SDS-PAGE) was carried out using Mini-PROTEAN TGX pre-cast gels (4-20\% resolving gel; Bio-Rad Laboratories Inc., Hercules, CA, USA) in Mini Protean II system (Bio-Rad). Samples were diluted at a ratio 1:1 with buffer and prepared under reducing and non-reducing conditions with or without the addition of $\beta$-mercaptoethanol, respectively. A broad-range molecular mass standard marker kit (SeeBlue ${ }^{\circledR}$ Plus2 Pre-Stained Standard, Invitrogen, Carlsbad, CA, USA) was added on a separate lane in the gel. Commercial pectinase and stem bromelain (Sigma-Aldrich) were also included in the gel as a reference.

\section{Statistical analysis}

Statistical analysis including analysis of variance (ANOVA) was performed using Microsoft Excel 2010 (27) and Statistical Analysis System (SAS) software v. 9.2 (28). The $t$-test was used to compare the mean values at a significance level of $a=0.05$. All tests were carried out in duplicate.

\section{RESULTS AND DISCUSSION}

\section{Effect of enzymatic pretreatment on CWM extract apparent} viscosity and flux profiles

The effect of pretreatment using $0.01 \%$ (by volume) pectinase, $0.05 \%$ (by volume) cellulase or the combination of both on the apparent viscosity of the CWM extract is shown in Fig. 1. Treatment with pectinase alone has yielded the lowest apparent viscosity of CWM extract with $1.03 \mathrm{mPa} \cdot \mathrm{s}$, which was a $12 \%$ reduction compared to the untreated extract (1.18 $\mathrm{mPa} \cdot \mathrm{s}$ ). The combination of $0.01 \%$ (by volume) pectinase and $0.05 \%$ (by volume) cellulase during the enzymatic pretreatment only managed to reduce the CWM extract apparent viscosity by $6.2 \%$, although the same amount of pectinase was used. A similar finding has been reported on the enzymatic pretreatment of other fruit juices, which might be due to the interaction between both enzymes (19). Meanwhile, treating the extract with $0.05 \%$ (by volume) cellulase alone led to 4.5 $\%$ apparent viscosity reduction. This finding indicates that pectin is the major polysaccharide in the CWM extract. Pectin content of $0.06 \%$ has been reported in the CWM extract while the content of cellulose and other polysaccharides was unknown (9). 


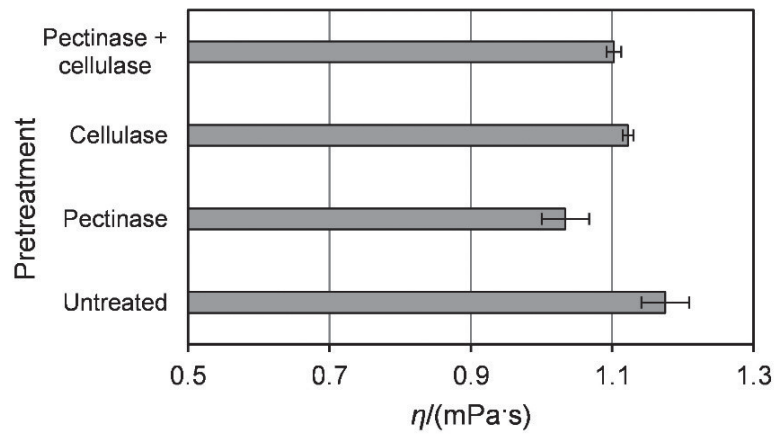

Fig. 1. Apparent viscosity ( $\eta$ ) after enzymatic pretreatments

The application of pectinase enzyme to reduce feed viscosity before membrane process is already an industrial practice to obtain an enhanced filtration rate during the process especially in fruit juice manufacture (29). The presence of pectin increases the viscosity of the plant extract, which can be attenuated by pectinase hydrolyzing the galacturonan backbone of pectic polysaccharides of plant tissues into small molecules like galacturonic acid, which results in a rapid decline of the viscosity of the extract $(30,31)$.

In this study, since the lowest apparent viscosity was obtained with $0.01 \%$ (by volume) pectinase, this enzyme was selected to pretreat CWM extract then processed by UF to establish the effect on flux and enzyme separation. The flux performance, enzyme recovery, and enzyme purity were compared between the pretreated and untreated samples in batch concentration mode two-stage UF system. Fig. 2a and Fig. $2 \mathrm{~b}$ show that the flux $(J)$ of pretreated $(0.01 \%$ pectinase) sample was higher than of the untreated samples in both UF stages and at shorter operation time ( $t$ ). In UF stage 1 (Fig. 2a), the final flux of the pretreated sample was $25.1 \mathrm{~kg} /\left(\mathrm{m}^{2} \cdot \mathrm{h}\right)$ (37 $\%$ higher) compared to $18.3 \mathrm{~kg} /\left(\mathrm{m}^{2} \cdot \mathrm{h}\right)$ of the untreated sample after the process was completed at $80 \%$ permeate recovery (PR). A similar finding was also observed during UF stage 2 as shown in Fig. 2b, where the final flux of the pretreated sample was $38 \%$ higher with $17.7 \mathrm{~kg} /\left(\mathrm{m}^{2} \cdot \mathrm{h}\right)$ as opposed to the flux of the untreated sample which was $12.8 \mathrm{~kg} /\left(\mathrm{m}^{2} \cdot \mathrm{h}\right)$ after the process was performed up to $\mathrm{VRF}=5$. These findings are the result of the viscosity reduction of the sample after the

a)

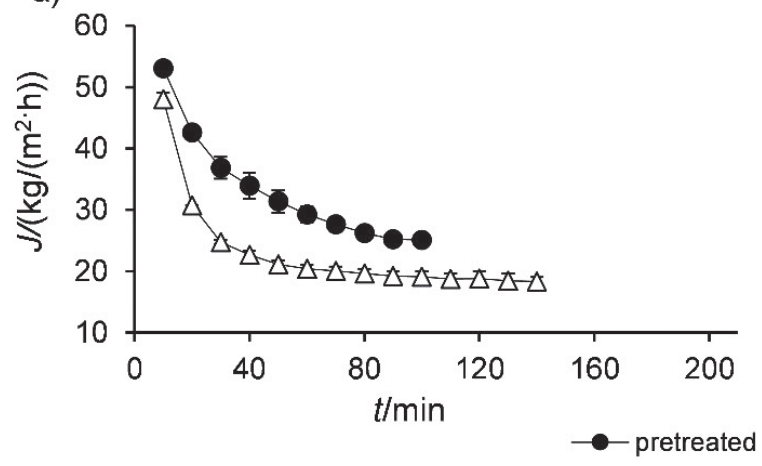

pretreatment (Fig. 1), as low feed viscosity directly influences flux performance during membrane processing (9).

In addition to viscosity drop, less fouling on the membrane surface would be expected since most of the pectin in the CWM extract was hydrolyzed by pectinase in the pretreatment stage. Pectin has been identified as one of the key components responsible for fouling layer formation by creating colloidal particles that tend to adsorb on the membrane surface (32). Its fibre-like structure can form a highly viscous gel-type layer on the membrane surface, which acts as an active membrane layer with fine porosity (33). Hydrophobicity of the gel layer may also increase due to interactions of weakly anionic polysaccharides such as pectin with other macromolecules such as proteins under high shearing condition (34), resulting in additional resistance and hindrance of the permeate flux, which leads to deterioration of membrane process efficiency.

Comparison of the pretreated and untreated samples after UF stage 1 and 2 regarding the enzyme purification fold and enzyme recovery is shown in Table 1 . There was no significant $(p>0.05$ ) change of enzyme purification fold observed in permeate of both samples in UF stage 1 (Table 1). This is expected since UF stage 1 is considered as a prefiltration stage utilized to remove components larger than bromelain such as polysaccharides and other colloids. Nonetheless, the enzyme recovery of the pretreated sample was $77.9 \%$, which was slightly higher $(p>0.05)$ than of the untreated sample (76.1\%). This higher transferring rate of the enzyme through the membrane could be due to retarded cake layer build up on the membrane surface. The pretreatment with pectinase has obviously resulted in a thinner and more porous barrier formed on the membrane surface, allowing for more bromelain to pass through than with the untreated sample.

The same phenomenon has likely occurred in the UF stage 2 (purification stage) which led to a lower enzyme recovery and purity in the retentate after the process was completed. The reduced fouling 'barrier' on the membrane surface in UF stage 2 has facilitated more bromelain to pass through the membrane (based on EA of the permeates of UF stage 2 as in Table 1), and consequently affected the final enzyme recovery of the pretreated sample which was only $40.6 \%$ compared

b)

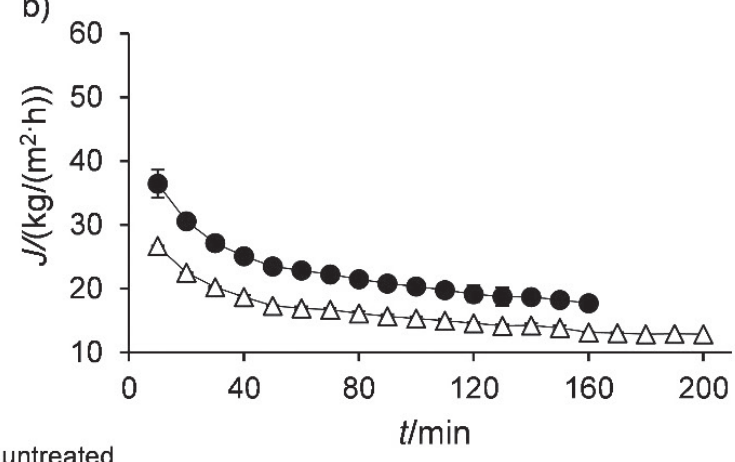

Fig. 2. Variation in permeate flux $(J)$ with time $(t)$ of pretreated and untreated feed in ultrafiltration stage: a) 1 and b) 2 
Table 1. Properties of pretreated and untreated samples in ultrafiltration (UF) stage 1 and 2

\begin{tabular}{|c|c|c|c|c|c|c|c|}
\hline Sample & $\begin{array}{l}\text { UF } \\
\text { stage }\end{array}$ & Sample & $\frac{\text { Enzyme activity }}{\mathrm{CDU} / \mathrm{mL}}$ & $\frac{\gamma(\text { protein })}{C D U / m L}$ & $\begin{array}{c}\text { Specific activity } \\
\text { CDU per mg of } \\
\text { protein }\end{array}$ & $\begin{array}{l}\text { Purity } \\
\text { fold }\end{array}$ & $\begin{array}{c}\text { Enzyme recovery } \\
\%\end{array}$ \\
\hline \multirow{5}{*}{$\begin{array}{l}\text { Pretreated } \\
\text { with } 0.01 \% \\
\text { (by volume) } \\
\text { pectinase }\end{array}$} & \multirow{3}{*}{1} & Feed & $(141.1 \pm 15.4)^{a}$ & $(1.6 \pm 0.0)^{\mathrm{ab}}$ & $(88.3 \pm 10.9)^{a}$ & - & - \\
\hline & & Permeate & $(137.0 \pm 12.9)^{\mathrm{a}}$ & $(1.5 \pm 0.0)^{\mathrm{a}}$ & $(91.5 \pm 7.5)^{\mathrm{a}}$ & $(1.04 \pm 0.0)^{\mathrm{a}}$ & $(77.9 \pm 1.3)^{a}$ \\
\hline & & Retentate & $(191.9 \pm 12.5)^{b}$ & $(1.8 \pm 0.1)^{\mathrm{b}}$ & $(109.2 \pm 0.3)^{a}$ & - & - \\
\hline & \multirow{3}{*}{2} & Feed & $(135.0 \pm 27.9)^{a b}$ & $(1.5 \pm 0.0)^{\mathrm{a}}$ & $(90.7 \pm 18.5)^{\mathrm{ab}}$ & - & - \\
\hline & & Permeate & $(93.8 \pm 16.6)^{a}$ & $(1.4 \pm 0.0)^{\mathrm{b}}$ & $(65.9 \pm 12.5)^{a}$ & - & - \\
\hline \multirow{6}{*}{ Untreated } & & Retentate & $(274.1 \pm 33.9)^{b}$ & $(2.1 \pm 0.1)^{c}$ & $(131.6 \pm 24.8)^{b}$ & $(1.45 \pm 0.1)^{b}$ & $(40.6 \pm 1.5)^{b}$ \\
\hline & \multirow[b]{2}{*}{1} & Feed & $(154.8 \pm 17.2)^{\mathrm{a}}$ & $(1.5 \pm 0.0)^{a}$ & $(102.9 \pm 14.4)^{a}$ & - & - \\
\hline & & Permeate & $(147.1 \pm 15.1)^{\mathrm{a}}$ & $(1.4 \pm 0.0)^{\mathrm{a}}$ & $(104.4 \pm 12.8)^{a}$ & $(1.02 \pm 0.0)^{\mathrm{a}}$ & $(76.1 \pm 0.8)^{a}$ \\
\hline & \multirow{3}{*}{2} & Feed & $(144.2 \pm 15.2)^{a b}$ & $(1.4 \pm 0.1)^{a}$ & $(103.5 \pm 20.0)^{\mathrm{ab}}$ & - & - \\
\hline & & Permeate & $(75.1 \pm 2.1)^{a}$ & $(1.2 \pm 0.3)^{b}$ & $(67.5 \pm 17.4)^{\mathrm{a}}$ & - & - \\
\hline & & Retentate & $(331.3 \pm 32.3)^{b}$ & $(2.1 \pm 0.5)^{c}$ & $(155.8 \pm 27.8)^{b}$ & $(1.51 \pm 0.0)^{b}$ & $(45.2 \pm 3.6)^{b}$ \\
\hline
\end{tabular}

Different letters in the same column of each UF stage section indicate the significant differences $(p<0.05)$. Different letters in the purity fold and enzyme recovery columns indicate no significant differences $(p<0.05)$. CDU=casein digestion unit

to the untreated sample (45.2\%). Similarly, the enzyme purity increment of the pretreated sample (1.45-fold) was lower ( $p>0.05)$ than of the control sample (1.51-fold). These findings indicate that the introduction of enzymatic pretreatment would promote higher flux during the UF process; however, it would also come at the cost of slightly lower enzyme purity and recovery in UF stage 2 . Thus, both factors need to be properly deliberated in the context of a full-scale application.

\section{Effect of diafiltration and concentration mode in UF stage 2 on flux performance}

In effort to improve flux performance and increase the purity of the enzyme by manipulating the feed viscosity, the diafiltration operational mode has been introduced prior to concentration step in UF stage 2 . The feed used for this process was pretreated with $0.01 \%$ pectinase and filtered by a $75-\mathrm{kDa}$ membrane in UF stage 1. Fig. 3 shows that the permeate flux $(J)$ was mostly constant during the diafiltration stage with an average flux of $37.1 \mathrm{~kg} /\left(\mathrm{m}^{2} \cdot \mathrm{h}\right)$. This is due to the addition of diluent (water) during diafiltration which has diluted the feed, thus minimized the concentration polarization effect and gel layer formation on the membrane surface (17). Furthermore, membrane fouling due to specific membrane-solute interactions (i.e. surface deposition or pore fouling) was less pronounced at a lower feed concentration (3). The hydrophilic characteristic of the ceramic membrane $\left(\mathrm{ZrO}_{2}\right)$ used in this process might have further assisted in the migration of permeate through the membrane especially at a low feed concentration.

After DVF of 3 was achieved, the operation in UF stage 2 then moved to the concentration mode by stopping the diluent addition while maintaining the re-circulation and removal of the retentate and permeates in the system, respectively.
At this stage, the flux has declined to $27.2 \mathrm{~kg} /\left(\mathrm{m}^{2} \cdot \mathrm{h}\right)$ at the end of the concentration process, which was about $26.7 \%$ flux reduction from the diafiltration stage (Fig. 3). This trend was expected since concentration polarization, and fouling issues are more prominent during this operation mode $(15,18)$, and was unavoidable although the feed has been initially pretreated with pectinase enzyme. Nevertheless, the final flux obtained after the concentration step in this combined process was significantly $(p<0.05)$ higher than the final flux $(17.7$ $\left.\mathrm{kg} /\left(\mathrm{m}^{2} \cdot \mathrm{h}\right)\right)$ attained from the standard concentration mode with the same VRF shown in Fig. 2 b.

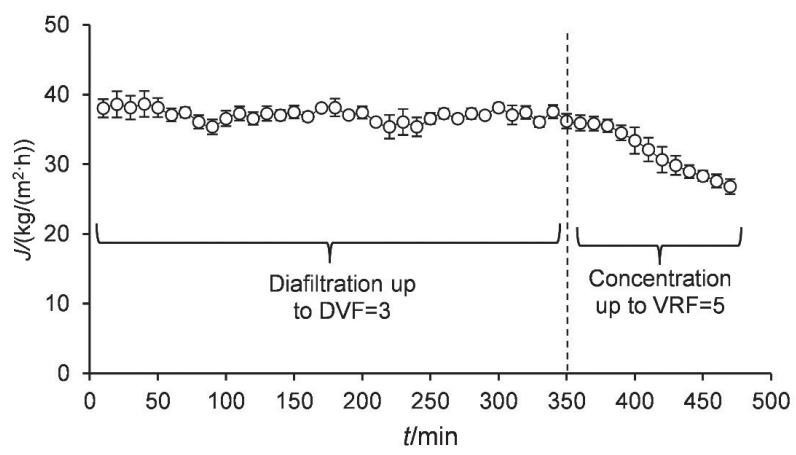

Fig. 3. Permeate flux $(J)$ profile during the operation of diafiltration followed by concentration in ultrafiltration stage 2 . DVF=diafiltration volume factor, $\mathrm{VRF}=$ volume reduction factor

Moreover, the process performance achieved in this study presents a substantial improvement from our previous work, which included a similar UF set-up but in a concentration mode only, where the extract was concentrated up to 15 VRF in UF stage 2 (15). The flux performance in the previous work had reduced over the time with the final flux attaining $6.2 \mathrm{~kg} /$ $\left(\mathrm{m}^{2} \cdot \mathrm{h}\right)$ only, which is $77.2 \%$ lower than the flux obtained in the 
current work. Also, the total processing time in the previous work was almost double (840 $\mathrm{min}$ ) than in the current work (470 min), all of which may lead to substantially improved process efficiency and feasibility. However, the approach used in the current study required a large volume of diluent (water) since the process started in the diafiltration mode. For 400-mL feed used in this study, $1200 \mathrm{~mL}$ of water was required. A concentration-diafiltration-concentration approach may be considered in the future in order to reduce the diluent needed during the diafiltration step without affecting the flux performance and enzyme purity.

\section{Effect of diafiltration and concentration mode in UF stage 2 on bromelain separation}

Enzyme and protein separation efficiency during the diafiltration and concentration modes in UF stage 2 was assessed by measuring the concentration of the solute in the feed and permeate, to determine the apparent sieving coefficient $(S)$ and observed rejection $\left(R_{\text {obs }}\right)$. Based on the obtained $S_{\mathrm{a}}$ and $R_{\text {obs' }}$ the enzyme activity and protein content of the feed during the diafiltration and concentration modes in UF stage 2 were modeled according to Eqs. 10 and 11 and compared to the experimental data as shown in Fig. 4 and Fig. 5. The figures indicate the agreement between the theoretical and experimental data. In Fig. 4a, the enzyme activity (EA) of the CWM extract has decreased by $33 \%$ from its initial value of 141.2 to 95.1 CDU/ $\mathrm{mL}$ after DVF=3 during the diafiltration process. The reduction might have been due to loss of the enzyme that has passed through or been absorbed by the membrane, likely impacted by reduced concentration polarization and consequently thinner and more porous fouling layer on the membrane surface during the diafiltration process. Nonetheless, the obtained $R_{\text {obs }}$ from this process was 0.87 , indicating that majority of the bromelain was retained by the membrane.

During the concentration mode, the EA increased substantially ( $145 \%$ ) leading to the final enzyme activity of $233.0 \mathrm{CDU} /$ $\mathrm{mL}$ after the UF stage 2 was completed at VRF=5 (Fig. 4b). This is in agreement with our previous work about the increment of enzyme activity in the UF system by increasing the VRF level (15). However, while EA has increased during this stage, the calculated $R_{\text {obs }}$ was 0.53 only, indicating that the process was partially efficient as it only managed to retain half of the enzyme concentration. a)

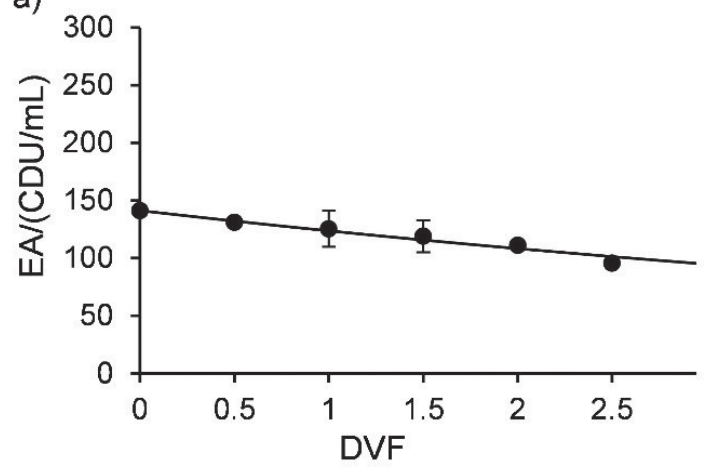

b)

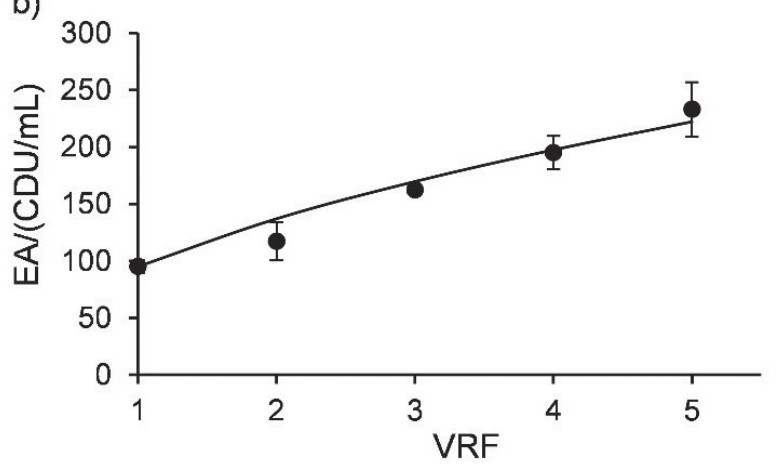

$(\bullet)$ experimental data $(-)$ theoretical data

Fig. 4. Evolution of enzyme activity (EA) in feed during the operation of: a) diafiltration, and b) concentration in ultrafiltration stage 2, at different diafiltration volume factor (DVF) or volume reduction factor (VRF), respectively. CDU=casein digestion unit

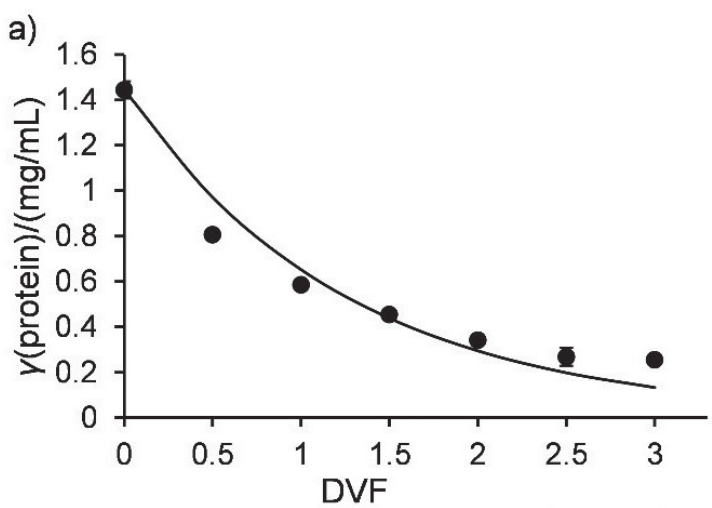

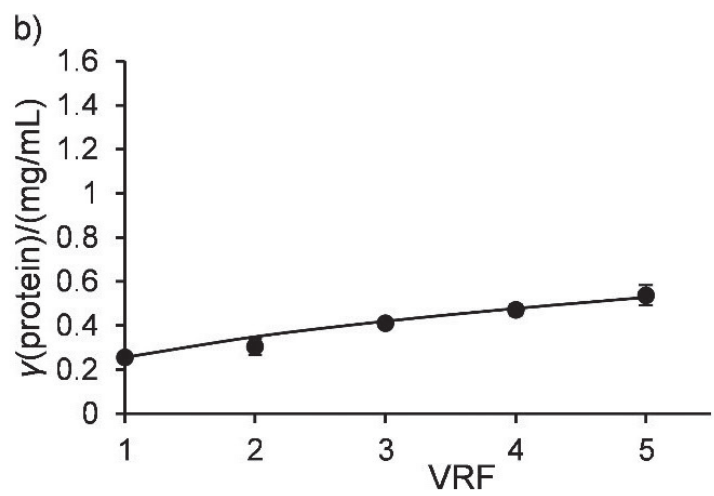

( ) theoretical data

Fig. 5. Evolution of protein content $(\gamma)$ in feed during the operation of: a) diafiltration, and b) concentration in ultrafiltration stage 2 , at different diafiltration volume factor (DVF) or volume reduction factor (VRF), respectively 
Meanwhile, the protein concentration significantly decreased, resulting in $82 \%$ reduction (from 1.44 to $0.26 \mathrm{mg} /$ $\mathrm{mL}$ ) (Fig. 5a) during the diafiltration step. This is further supported by a low observed rejection $\left(R_{\mathrm{obs}}=0.20\right)$. Apparently, the retarded formation of the fouling layer on the membrane surface has allowed permeation of lower molecular mass proteins, peptides and amino acids, while retaining most of the valuable enzyme. The protein content has then increased by $54 \%$ to $0.40 \mathrm{mg} / \mathrm{mL}$ (Fig. $5 \mathrm{~b}$ ) during the concentration step giving $R_{\text {obs }}=0.45$.

While EA and protein content declined during the diafiltration process, specific activity (SA) has risen substantially from its initial value of 97.7 to $372.2 \mathrm{CDU}$ per mg of protein, which resulted in the increment of the enzyme purity by 3.8-fold (Fig. 6) primarily due to substantial reduction of the protein content of the feed during diafiltration operation. The SA has further increased during the concentration step, reaching its final value of $433.2 \mathrm{CDU}$ per $\mathrm{mg}$ of protein resulting in a total of 4.4-fold purity increment. In comparison, a purity increment of 12 -fold of protease was reported from pretreated tuna spleen extract by using a similar diafiltration and concentration mode approach (17). Nevertheless, in terms of bromelain purification, the current method is comparable with other purification techniques including aqueous two-phase system (3.2-fold purity) (14), reverse micellar system (4-fold purity) (35) and ethanol precipitation (3.1-fold purity) (36).

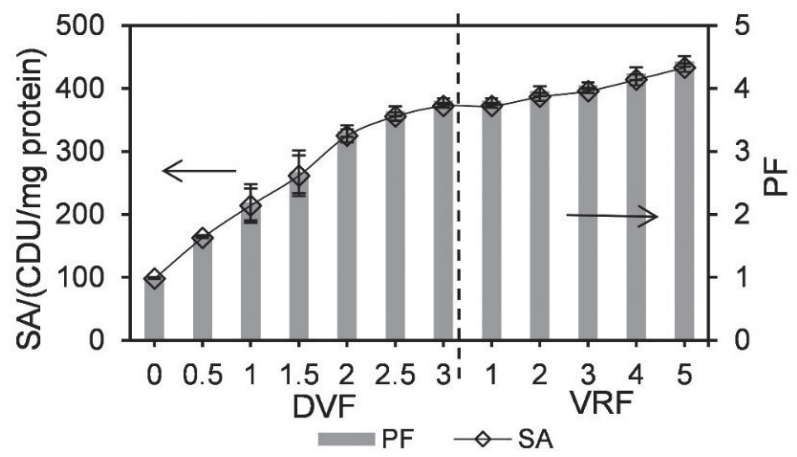

Fig. 6. Variation of enzyme specific activity (SA) and purification fold (PF) increment in the feed during the operation of diafiltration followed by concentration in ultrafiltration stage 2. Diafiltration volume factor (DVF) of 3 and volume reduction factor (VRF) of 1 refer to the same operating condition. $\mathrm{CDU}=$ casein digestion unit

The fractionation efficiency of the process was further expressed by selectivity $(\psi)$ of the membrane. Based on obtained observed rejection $\left(R_{\text {obs }}\right)$ and apparent sieving coefficient $\left(S_{\mathrm{a}}\right)$, the membrane selectivity $(\psi)$ during the diafiltration and concentration was determined at 5.8 and 1.1 , respectively. The $\psi$ values showed that fractionation of bromelain enzyme from non-related protein was higher during the diafiltration process, which further proved benefits of inclusion of diafiltration step in UF stage 2 for bromelain purification.

Despite the promising increment of enzyme purity, the final enzyme recovery (ER) upon process completion was only $46 \%$, as indicated by the mass balance between the enzyme and protein in the feed, permeate and retentate in UF stage 2 (Fig. 7). Almost similar proportions of EA (approx. $46 \%$ ) were observed in the retentate and permeate, signifying the permeation of some enzyme through the membrane. Nonetheless, the process has managed to separate most of the soluble protein $(81 \%)$ into the permeate. On the other hand, the total sum of EA and PR proportions in the retentate and permeate of UF stage 2 was only 93.3 and $91.2 \%$, respectively, out of $100 \%$ of the total mass balance in the feed, indicating some protein and enzyme losses in the system. This might be due to several reasons such as: (i) protein and enzyme oxidation and conformational changes caused by continual recycling of the extract around the UF module, and (ii) protein and enzyme losses by irreversible adsorption on the surface of the UF membrane and/or within its pores $(13,15)$.

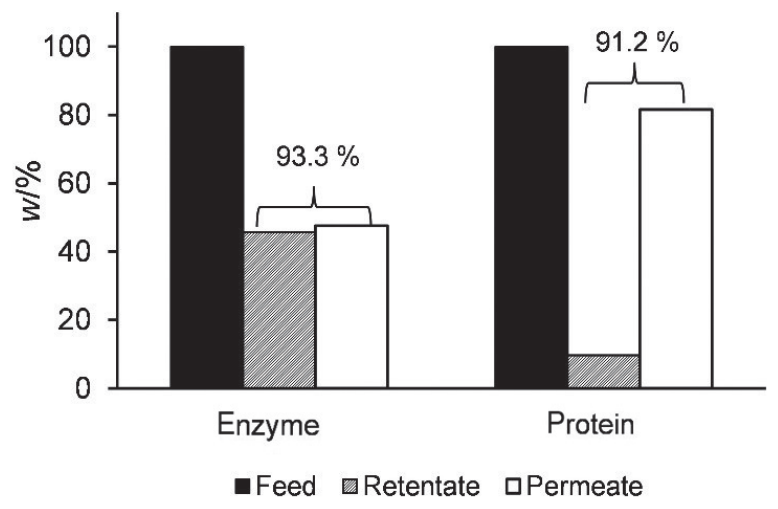

Fig. 7. Mass fraction $(w)$ of enzyme and protein in the feed, retentate and permeate of ultrafiltration stage 2

Nevertheless, the increment of purity fold in this study had substantially surpassed the purity fold achieved in our previous work, where 2.5 -fold purity was achieved when the UF stage 2 was performed in concentration mode only up to VRF of 15 (15). The purity in the current work exceeds targeted 2- to 4-fold purification requirement necessary for commercialization purposes (9). The achieved purity apparently stemmed from the employment of the diafiltration step in UF stage 2.

\section{Gel electrophoresis}

The bromelain purification process was further confirmed by the gel electrophoresis analysis. Observations of the protein patterns of the samples were made under reducing and non-reducing conditions (Fig. 8). Under both conditions, the purified bromelain concentrate (lanes 3 and 8) showed clearer bands at molecular mass of approx. $23 \mathrm{kDa}$ compared to the feed of UF stage 1 (lanes 1 and 6) and feed of UF stage 2 (lanes 2 and 7), indicating reasonably good purification of the enzyme. A similar band was also obtained for the commercial stem bromelain under the same conditions (lanes 4 and 9). The range of $M$ of different types of bromelain is from 23.4 to $35.73 \mathrm{kDa}(10)$. 


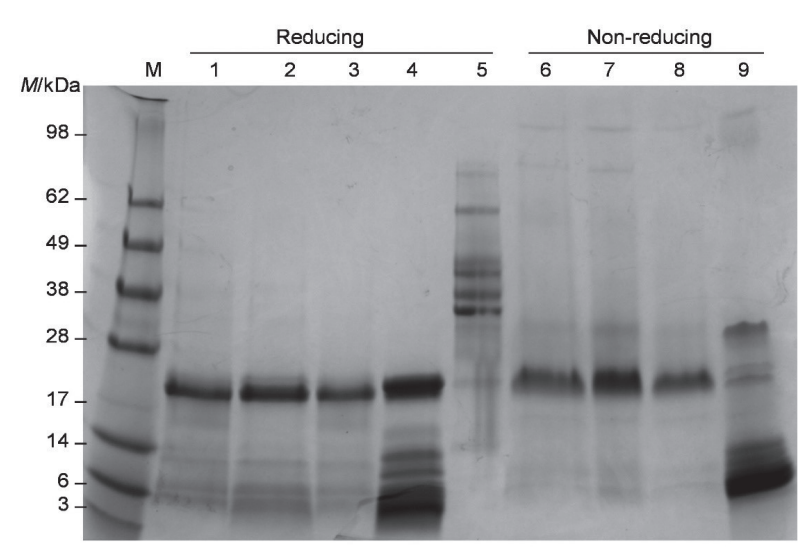

Fig. 8. Protein patterns under reducing and non-reducing conditions. $\mathrm{M}=$ molecular mass marker, lanes 1 and $6=$ feed of UF stage 1, lanes 2 and $7=$ feed of UF stage 2 , lanes 3 and $8=$ purified bromelain concentrate, lanes 4 and $9=$ commercial stem bromelain, lane $5=$ commercial pectinase

Since the feed used in the UF process has been pretreated with commercial pectinase, observation on the trace of pectinase in the final concentrate was also performed. The two-stage UF system in this study could only separate molecules in the range between 10 and $75 \mathrm{kDa}$, which would also include pectinase as it has $M=30-65 \mathrm{kDa}$ (31). Any trace of pectinase in the final bromelain concentrate may affect the protein content determination, which would result in a lower specific activity of the bromelain. However, pectinase appeared absent from the purified bromelain concentrate (lanes 3 and 8) as its bands were visible in the range between 33 and $70 \mathrm{kDa}$ (lane 5, Fig. 6). This does not necessarily mean that the pectinase was not present but that its concentration was below the threshold of the analytical method. Thus, it is recommended to perform the pretreatment step using immobilized pectinase for the benefits of the operation.

\section{CONCLUSIONS}

Pectinase has provided the most significant reduction of crude waste mixture extract apparent viscosity, which led to the improvement of the flux performance during the two-stage UF process. The pretreatment likely prevented the formation of a thick fouling layer on the membrane surface, which has resulted in a greater enzyme recovery in UF stage 1 but lower enzyme purity and recovery in UF stage 2 than in the control sample. Employment of diafiltration mode prior to concentration mode in UF stage 2 has assisted in maintaining high flux while increasing the enzyme purity. A $46 \%$ enzyme recovery was obtained after UF stage 2 with the employment of diafiltration and concentration operational modes during the process. Nevertheless, the process has managed to increase the enzyme purity to 4.4-fold, which was accommodated by the high membrane selectivity during the diafiltration process. This increment has surpassed the purity increment achieved in our previous study and even higher than the purity requirement for commercialization purpose. However, the diafiltration process in this study required high volume of diluent. Thus, performing the process in the combination of concentration-diafiltration-concentration modes may be considered to reduce the diluent consumption while sustaining the process performance for the industrial applications.

\section{ACKNOWLEDGMENTS}

The authors gratefully acknowledge the Ministry of Education Malaysia and Universiti Putra Malaysia (UPM) for providing the PhD scholarship for M.Z.M. Nor. The authors would also like to acknowledge the financial support for the project by Victoria University, Australia.

\section{REFERENCES}

1. Dutré $B$, Trägrdh G. Macrosolute-microsolute separation by ultrafiltration: A review of diafiltration processes and applications. Desalination. 1994;95(3):227-67. https://doi.org/10.1016/0011-9164(94)00063-8

2. Li Z, Youravong W, H-Kittikun A. Separation of proteases from yellowfin tuna spleen by ultrafiltration. Bioresour Technol. 2006;97(18):2364-70.

https://doi.org/10.1016/j.biortech.2005.10.019

3. Datta D, Bhattacharjee S, Nath A, Das R, Bhattacharjee C, Datta S. Separation of ovalbumin from chicken egg white using two-stage ultrafiltration technique. Sep PurifTechnol. 2009;66(2):353-61.

https://doi.org/10.1016/j.seppur.2008.12.016

4. Ting BPCP, Pouliot Y, Juneja LR, Okubo T, Gauthier SF, Mine $Y$. On the use of ultrafiltration for the concentration and desalting of phosvitin from egg yolk protein concentrate. Int J Food Sci Technol. 2010;45(8):1633-40. https://doi.org/10.1111/j.1365-2621.2010.02311.x

5. Aspelund MT, Glatz CE. Purification of recombinant plantmade proteins from corn extracts by ultrafiltration. J Membr Sci. 2010;353(1-2):103-10.

https://doi.org/10.1016/j.memsci.2010.02.036

6. Jang $\mathrm{HL}$, Liceaga AM, Yoon KY. Purification, characterisation and stability of an antioxidant peptide derived from sandfish (Arctoscopus japonicus) protein hydrolysates. J Funct Foods. 2016;20:433-42.

https://doi.org/10.1016/j.jff.2015.11.020

7. Nor MZM, Ramchandran L, Duke M, Vasiljevic T. Application of membrane-based technology for purification of bromelain. Int Food Res J. 2017;24(4):1685-96.

8. Bresolin IRAP, Bresolin ITL, Silveira E, Tambourgi EB, Mazzola PG. Isolation and purification of bromelain from waste peel of pineapple for therapeutic application. Braz Arch Biol Technol. 2013;56:971-9. https://doi.org/10.1590/S1516-89132013000600012

9. Nor MZM, Ramchandran L, Duke M, Vasiljevic T. Characteristic properties of crude pineapple waste extract for bromelain purification by membrane processing. J Food Sci Technol. 2015;52(11):7103-12. https://doi.org/10.1007/s13197-015-1812-5 
10. Arshad ZIM, Amid A, Yusof F, Jaswir I, Ahmad K, Loke SP. Bromelain: An overview of industrial application and purification strategies. Appl Microbiol Biotechnol. 2014;98(17):7283-97. https://doi.org/10.1007/s00253-014-5889-y

11. Lopes FLG, Baptista Severo Jr. J, de Souza RR, Diniz Ehrhardt D, Curvelo Santana JC, Tambourgi EB. Concentration by membrane separation processes of a medicinal product obtained from pineapple pulp. Braz Arch Biol Technol. 2009;52(2):457-64.

https://doi.org/10.1590/S1516-89132009000200024

12. Lopes FLG, Sbruzzi D, Gomes Barros KV, Ferrari Ferreira J, Curvelo Santana JC, de Souza RR, Basile Tambourgi E. Viability in the production of a drug extracted from Ananas comosus by a flat membrane system. Braz Arch Biol Technol. 2012;55(3):465-70.

https://doi.org/10.1590/S1516-89132012000300018

13. Doko MB, Bassani V, Casadebaig J, Cavailles L, Jacob M. Preparation of proteolytic enzyme extracts from Ananas comosus L., Merr. fruit juice using semipermeable membrane, ammonium sulfate extraction, centrifugation and freeze-drying processes. Int J Pharm. 1991;76(3):199-206. https://doi.org/10.1016/0378-5173(91)90272-P

14. Hebbar UH, Sumana B, Hemavathi AB, Raghavarao KSMS. Separation and purification of bromelain by reverse micellar extraction coupled ultrafiltration and comparative studies with other methods. Food Bioprocess Technol. 2012;5(3):1010-8.

https://doi.org/10.1007/s11947-010-0395-4

15. Nor MZM, Ramchandran L, Duke M, Vasiljevic T. Separation of bromelain from crude pineapple waste mixture by a twostage ceramic ultrafiltration process. Food Bioprod Process. 2016;98:142-50.

https://doi.org/10.1016/j.fbp.2016.01.001

16. Cheryan M. Ultrafiltration handbook. Lancaster, PA, USA: Technomic Publishing Co. Inc.; 1986.

17. Li Z, H-Kittikun A, Youravong W. Purification of protease from pretreated tuna spleen extract by ultrafiltration: An altered operational mode involving critical flux condition and diafiltration. Sep Purif Technol. 2009;66(2):368-74. https://doi.org/10.1016/j.seppur.2008.12.018

18. Nor MZM, Ramchandran L, Duke M, Vasiljevic T. Integrated ultrafiltration process for the recovery of bromelain from pineapple waste mixture. J Food Process Eng. 2017;40(3):e12492.

https://doi.org/10.1111/jfpe.12492

19. Carvalho LMJ, Castro IMD, Silva CAB. A study of retention of sugars in the process of clarification of pineapple juice (Ananas comosus, L. Merril) by micro- and ultra-filtration. J Food Eng. 2008;87(4):447-54.

https://doi.org/10.1016/j.jfoodeng.2007.12.015

20. Shamsudin R, Wan Daud WR, Takrif MS, Hassan O, Ilicali C. Rheological properties of Josapine pineapple juice at different stages of maturity. Int J Food Sci Technol. 2009;44(4):757-62.

https://doi.org/10.1111/j.1365-2621.2008.01893.x
21. Rheoplus v. 2.3 software, Anton Paar, Ostfildern, Germany; 2006. Available from: https://www.anton-paar.com.

22. Cleaning and sanitation/sterilisation guidelines: Membralox users' manual. Victoria, Australia: Pall Corporation; 2007.

23. Hausmann A, Sanciolo P, Vasiljevic T, Weeks M, Schroën $K$, Gray S, Duke M. Fouling mechanisms of dairy streams during membrane distillation. J Membr Sci. 2013;441:102-11. https://doi.org/10.1016/j.memsci.2013.03.043

24. MurachiT. Bromelain enzymes. Meth Enzymol. 1970;19:27384.

25. van Reis R, Saksena S. Optimization diagram for membrane separations. J Membr Sci. 1997;129:19-29.

https://doi.org/10.1016/S0376-7388(96)00319-5

26. Wang XL, Zhang C, Ouyang P. The possibility of separating saccharides from a $\mathrm{NaCl}$ solution by using nanofiltration in diafiltration mode. J Membr Sci. 2002;204(1-2):271-81. https://doi.org/10.1016/S0376-7388(02)00050-9

27. Microsoft Excel Windows 7 edition, Microsoft Corporation, Washington, USA; 2016. Available from: https://office.microsoft.com/en-us/excel.

28. Statistical Analysis Software (SAS) v. 9.2, SAS Institute, Cary, NC, USA; 2013. Available from: https://www.sas.com.

29. Girard B, Fukumoto LR. Membrane processing of fruit juices and beverages: A review. Crit Rev Biotechnol. 2000;20(2):112-75.

https://doi.org/10.1080/07388550008984168

30. Alkorta I, Garbisu C, Llama MJ, Serra JL. Industrial applications of pectic enzymes: A review. Process Biochem. 1998;33(1):21-8.

https://doi.org/10.1016/S0032-9592(97)00046-0

31. Rajdeo K, Harini T, Lavanya K, Fadnavis NW. Immobilization of pectinase on reusable polymer support for clarification of apple juice. Food Bioprod Process. 2016;99:12-9. https://doi.org/10.1016/j.fbp.2016.03.004

32. Saha NK, Balakrishnan M, Ulbricht M. Sugarcane juice ultrafiltration: FTIR and SEM analysis of polysaccharide fouling. J Membr Sci. 2007;306(1-2):287-97. https://doi.org/10.1016/j.memsci.2007.09.006

33. Rai P, De S. Clarification of pectin-containing juice using ultrafiltration. Curr Sci 2009;96(10):1361-71.

34. Qomarudin Q, Orbell JD, Ramchandran L, Gray SR, Stewart $M B$, Vasiljevic T. Properties of beta-lactoglobulin/alginate mixtures as a function of component ratio, $\mathrm{pH}$ and applied shear. Food Res Int. 2015;71:23-31. https://doi.org/10.1016/j.foodres.2015.02.024

35. Chaurasiya RS, Hebbar HU. Extraction of bromelain from pineapple core and purification by RME and precipitation methods. Sep Purif Technol. 2013;111:90-7. https://doi.org/10.1016/j.seppur.2013.03.029

36. Silvestre MPC, Carreira RL, Silva MR, Corgosinho FC, Monteiro MRP, Morais HA. Effect of $\mathrm{pH}$ and temperature on the activity of enzymatic extracts from pineapple peel. Food Bioprocess Technol. 2012;5(5):1824-31. https://doi.org/10.1007/s11947-011-0616-5 